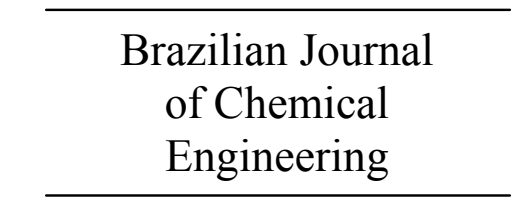

ISSN 0104-6632

Printed in Brazil

www.abeq.org.br/bjche

Vol. 31, No. 01, pp. 35 - 46, January - March, 2014

\title{
ON THE PREDICTION OF PICKUP AND SALTATION VELOCITIES IN PNEUMATIC CONVEYING
}

\author{
L. M. Gomes ${ }^{1 *}$ and A. L. Amarante Mesquita ${ }^{2 *}$ \\ ${ }^{1}$ Faculdade de Ciências Naturais, Campus de Marabá, UFPA, Phone: (94) 2101-5900, Fax: (94) 2101-5901, \\ Folha 17, Quadra 04, Lote Especial, CEP: 68505-080, Marabá - PA, Brazil. \\ E-mail: luizmg@ufpa.br \\ ${ }^{2}$ Laboratório de Transporte Pneumático, Faculdade de Engenharia Mecânica, UFPA, R. Augusto Correia 01, \\ CEP: 66075-110, Belém - PA, Brazil. \\ E-mail: andream@ufpa.br
}

(Submitted: January 26, 2012 ; Revised: May 01, 2013 ; Accepted: May 10, 2013)

\begin{abstract}
This paper presents a comparative study of the critical pickup and saltation velocities of particles in horizontal pipelines for pneumatic conveying design. A comparative study is performed using different existing correlations in the literature for the determination of the minimum velocity of transport as a function of the particle and pipe diameter, particle density, solid mass flow rate and particle sphericity. Their limitations and difficulties in predicting those critical velocities are analyzed. For the pickup velocity, an experimental study was also carried out in order to support the analysis. Recommendations are presented on the use of such correlations.

Keywords: Pickup velocity; Saltation velocity; Pneumatic conveying; Gas-solid flow.
\end{abstract}

\section{INTRODUCTION}

Pneumatic conveying is a process in which solid particulate materials are conveyed by gas flow through pipeline systems. Nowadays, this type of transport has become a popular technique in the field of particulate materials. Applications for pneumatic conveying systems can be found in many industrial areas, such as ore processing and in the chemical, pharmaceutical, agricultural and food processing industries.

A key parameter for successful operation of a pneumatic conveying system is the minimum velocity required for particle entrainment, also known as the pickup velocity. The minimum velocity to maintain the particulate flow is called the saltation velocity. The knowledge of these velocities is critical for an accurate design of a pneumatic conveying system. If the fluid velocity is much higher than is necessary, the system is subjected to unnecessary energy losses, particle attrition and excessive pipe erosion. A fluid velocity below these critical velocities can result in clogged pipelines.

Both pickup and saltation velocities are functions of the particle properties, such as size, density and sphericity, fluid properties, such as density and viscosity, and the main process variable, the solid mass flow rate. Despite the existence of advanced modeling for turbulent gas-solid flows (Huilin et al., 2003) and modern powerful numerical methods to solve this complex flow model (Chu and $\mathrm{Yu}, 2008$; Pirker et al., 2010), the empirical correlation for both pickup and saltation velocities still remains as a practical issue for industrial pneumatic conveying systems design

Several attempts have been made in the past to predict the minimum conveying velocity, but, unfortunately, the majority of existing approaches have

*To whom correspondence should be addressed 
several limitations and contradictions, as reviewed by Yi et al. (1998) and Rabinovich and Kalman (2008).

The goal of this paper is to provide a critical analysis of the pickup and saltation velocities, considering the influence of parameters such as particle and pipeline diameters, particle density and solids loading ratio. For the pickup velocity, an experimental study was also carried out to support the analysis. Thus, this paper presents recommendations on the limitations of the existing correlations.

\section{LITERATURE REVIEW}

The minimum transport velocity is defined as the lowest velocity at which particles can be transported inside a pipeline in a stable manner without deposition on the bottom of the pipe. The saltation velocity is defined as the gas velocity in a horizontal pipeline in which the particles begin to fall from their state of suspension and are deposited at the bottom of the pipeline.

The pickup velocity is defined as the gas velocity necessary to suspend the particles initially at rest in the bottom of the pipeline (see Figure 1), or it may be defined as the fluid velocity required to initiate a sliding motion, rolling and suspension of the particles.

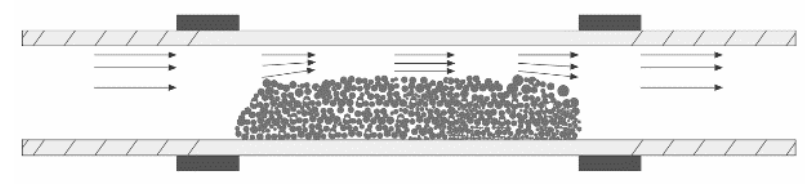

(a)

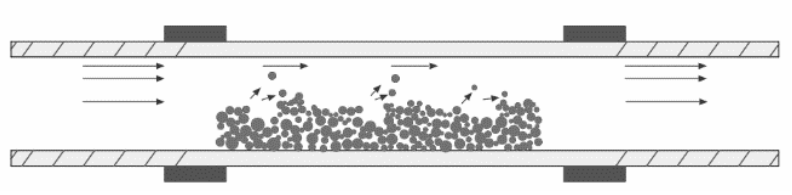

(b)

Figure 1: (a) Particles at rest in the bottom of the pipeline. Air velocity less than the pickup velocity. (b) Particles are dragged by the air stream. Air velocity equal to or greater than the pickup velocity.

The main correlations found in the literature that are used for predicting the critical pickup and saltation velocities are presented below. These correlations are analyzed in this work.

\section{Main Correlations Used for Predicting Critical Saltation Velocity}

Rizk (1976)

$\zeta=\frac{\mathrm{Ws}}{\rho_{\mathrm{f}} \mathrm{U}_{\mathrm{S}} \mathrm{A}}=\left(\frac{1}{10^{\mathrm{d}}}\right) \mathrm{Fr}_{\mathrm{S}}^{\mathrm{x}}$

where:

$\mathrm{Fr}_{\mathrm{S}}=\mathrm{U}_{\mathrm{S}} / \sqrt{\mathrm{gD}_{\mathrm{T}}}$ (Froude number at the Saltation velocity), $\mathrm{d}=1.44 \mathrm{~d}_{\mathrm{p}}+1.96, \mathrm{x}=1.1 \mathrm{~d}_{\mathrm{p}}+2.5$, ( $\mathrm{d}$ and $\mathrm{x}$ in $\mathrm{mm}), \zeta$ is the solids loading ratio, $\mathrm{W}_{\mathrm{S}}$ is the solids mass flow rate, $d_{p}$ is the particle diameter, $D_{T}$ is the pipe diameter, $U_{S}$ is the saltation velocity, $\rho_{\mathrm{f}}$ is the fluid density, $g$ is the acceleration of gravity and $\mathrm{A}$ is the cross-sectional area of pipe.

\section{Matsumoto et al. (1977)}

For:

$$
\begin{aligned}
& \mathrm{d}_{\mathrm{p}}>1.39 \mathrm{D}_{\mathrm{T}}\left(\frac{\rho_{\mathrm{p}}}{\rho_{\mathrm{f}}}\right)^{-0.74} \\
& \zeta=0.373\left(\frac{\rho_{\mathrm{p}}}{\rho_{\mathrm{f}}}\right)^{1.06}\left(\frac{\mathrm{U}_{\mathrm{t}}}{10 \sqrt{\mathrm{gd}_{\mathrm{p}}}}\right)^{-3.7}\left(\frac{\mathrm{U}_{\min }}{10 \sqrt{\mathrm{gD}_{\mathrm{T}}}}\right)^{3.61}
\end{aligned}
$$

For:

$d_{p}<1.39 D_{T}\left(\frac{\rho_{p}}{\rho_{\mathrm{f}}}\right)^{-0.74}$

$\zeta=5560\left(\frac{\mathrm{d}_{\mathrm{p}}}{\mathrm{D}_{\mathrm{T}}}\right)^{1.43}\left(\frac{\mathrm{U}_{\min }}{10 \sqrt{\mathrm{gD}_{\mathrm{T}}}}\right)^{3.61}$

where $\rho_{p}$ is the particle density, $U_{t}$ is the terminal velocity and $U_{\min }$ is the minimum conveying velocity.

Schade (1987), apud Yi et al. (1998)

$\frac{\mathrm{U}_{\mathrm{S}}}{\sqrt{\mathrm{gD}_{\mathrm{T}}}}=\zeta^{0.11}\left(\frac{\mathrm{D}_{\mathrm{T}}}{\mathrm{d}_{\mathrm{p}}}\right)^{0.025}\left(\frac{\rho_{\mathrm{p}}}{\rho_{\mathrm{f}}}\right)^{0.34}$

\section{Weber (1981)}

For: 
$\mathrm{U}_{\mathrm{t}} \leq 3 \mathrm{~m} / \mathrm{s}$

$\mathrm{Fr}_{\min }=\left(7+\frac{8}{3} \mathrm{U}_{\mathrm{t}}\right) \zeta^{0.25}\left(\frac{\mathrm{d}_{\mathrm{p}}}{\mathrm{D}_{\mathrm{T}}}\right)^{0.1}$

For:

$\mathrm{U}_{\mathrm{t}}>3 \mathrm{~m} / \mathrm{s}$

$\mathrm{Fr}_{\min }=15 \zeta^{0.25}\left(\frac{\mathrm{d}_{\mathrm{p}}}{\mathrm{D}_{\mathrm{T}}}\right)^{0.1}$

where $\mathrm{Fr}_{\min }$ is the Froude number at the minimum conveying velocity.

\section{Geldart and Ling (1992)}

For:

$\frac{\mathrm{G}_{\mathrm{s}}}{\mathrm{D}_{\mathrm{t}}}<47000$

$\mathrm{U}_{\min }=1.5 \mathrm{G}_{\mathrm{s}}^{0.465} \mathrm{D}_{\mathrm{T}}^{-0.01} \mu^{0.55} \rho_{\mathrm{f}}^{-0.42}$

For:

$\frac{\mathrm{G}_{\mathrm{s}}}{\mathrm{D}_{\mathrm{t}}}<47000$

$\mathrm{U}_{\min }=8.7 \mathrm{G}_{\mathrm{s}}^{0.302} \mathrm{D}_{\mathrm{T}}^{0.153} \mu^{0.55} \rho_{\mathrm{f}}^{-0.42}$

where, $\mu$ (in $\mathrm{kg} / \mathrm{m} . \mathrm{s}$ ) is the dynamic viscosity of the gas and $\mathrm{G}_{\mathrm{s}}\left(\right.$ in $\mathrm{kg} / \mathrm{m}^{2} . \mathrm{s}$ ) is the solids flux.

Ochi (1991)

$\frac{\mathrm{U}_{\mathrm{s}}}{\sqrt{\mathrm{gd}_{\mathrm{p}}}}=1.05 \mathrm{f}_{\mathrm{s}}^{0.47}\left(\frac{\mathrm{U}_{\mathrm{t}}}{\sqrt{\mathrm{gd}_{\mathrm{p}}}}\right)^{0.82} \zeta^{0.25}$

where $f_{s}$ is the particle friction coefficient with the pipeline wall.

Cabrejos and Klinzing (1994)

$\frac{\mathrm{U}_{\mathrm{S}}}{\sqrt{\mathrm{gd}_{\mathrm{p}}}}=\frac{\mathrm{U}_{\mathrm{s} 0}}{\sqrt{\mathrm{gd}_{\mathrm{p}}}}+0.00224\left(\frac{\rho_{\mathrm{p}}}{\sqrt{\rho_{\mathrm{f}}}}\right)^{1.25} \zeta^{0.5}$

\section{Kalman and Rabinovich (2008)}

For:

$$
\left(1+30 \mathrm{C}_{\mathrm{V}}^{0.35}\right)^{2.33} \mathrm{Ar}<2450
$$

$\frac{\rho_{\mathrm{p}} \mathrm{d}_{\mathrm{p}} \mathrm{U}_{\mathrm{mp}}}{\mu}=14.3\left(\left(1+30 \mathrm{C}_{\mathrm{V}}^{0.35}\right)^{2.33} \mathrm{Ar}\right)^{0.1}$

where, $\mathrm{U}_{\mathrm{mp}}$ is the minimum pressure velocity and, $\operatorname{Ar}=\frac{\rho_{\mathrm{f}}\left(\rho_{\mathrm{p}}-\rho_{\mathrm{f}}\right) \mathrm{gd}_{\mathrm{p}}^{3}}{\mu^{2}},($ Archimedes number $)$

For,

$\left(\left(\frac{1-\varepsilon}{\varepsilon}\right)^{0.1}+30 \mathrm{C}_{\mathrm{V}}^{0.35}\right)^{2.33} \mathrm{Ar}$

$\frac{\rho_{\mathrm{f}} \mathrm{d}_{\mathrm{p}} \mathrm{U}_{\mathrm{mp}}}{\mu}=1.1\left(\left(\left(\frac{1-\varepsilon}{\varepsilon}\right)^{0.1}+30 \mathrm{C}_{\mathrm{V}}^{0.35}\right)^{2.33} \mathrm{Ar}\right)^{3 / 7}$

where,

$\mathrm{C}_{\mathrm{V}}=\frac{\zeta \rho_{\mathrm{f}}}{\rho_{\mathrm{p}}+\zeta \rho_{\mathrm{f}}},($ solids volumetric concentration $)$

\section{Main Correlations Used for Predicting the Critical Pickup Velocity}

Cabrejos and Klinzing (1992)

$$
\begin{aligned}
\mathrm{U}_{\mathrm{p}}= & {\left[1.27 \mathrm{Ar}^{-1 / 3}+0.036 \mathrm{Ar}^{1 / 3}+0.45\right] } \\
& {\left[0.70 \mathrm{Ar}^{-1 / 5}+1\right] \mathrm{U}_{\mathrm{p} 0} }
\end{aligned}
$$

where $\mathrm{U}_{\mathrm{p} 0}$ is the pickup velocity of a particle alone and,

$\mathrm{U}_{\mathrm{p} 0}=\frac{\pi}{8}\left[1-\left(\frac{\mathrm{d}_{\mathrm{p}}}{\mathrm{D}_{\mathrm{r}}}\right)^{1.5}\right] \sqrt{\frac{4}{3} \frac{\mathrm{f}_{\mathrm{s}} \mathrm{gd}}{\mathrm{C}_{\mathrm{D}}}\left(\frac{\rho_{\mathrm{p}}-\rho_{\mathrm{f}}}{\rho_{\mathrm{f}}}\right)}$

coarse particle

$C_{D}$ is the drag coefficient of the particle. 


$$
\begin{aligned}
& 1.54 \times 10^{-4}\left[1-\left(\frac{d_{p}}{D_{T}}\right)^{1.5}\right]^{-2} C_{D} \rho_{f} d_{p}^{4}\left(\frac{U_{p o}^{7}}{v^{3} D_{T}}\right)^{\frac{1}{2}} \\
& =f_{s}\left[\frac{\pi}{6} g_{p}^{3}\left(\rho_{p}-\rho_{f}\right)+1.302 \times 10^{-6} d_{p}-6.35 \times 10^{-3} \rho_{f} d_{p}^{3}\left(\frac{U_{p o}^{21}}{v^{5} D_{T}^{3}}\right)^{\frac{1}{8}}\right] \text { (fine particle) }
\end{aligned}
$$

$v$ is the kinematic viscosity.

\section{Cabrejos and Klinzing (1994)}

$\frac{\mathrm{U}_{\mathrm{p}}}{\sqrt{\mathrm{gd}_{\mathrm{p}}}}=0.0428 \operatorname{Re}_{\mathrm{p}} 0.175\left(\frac{\mathrm{D}_{\mathrm{T}}}{\mathrm{d}_{\mathrm{p}}}\right)^{0.25}\left(\frac{\rho_{\mathrm{p}}}{\rho_{\mathrm{f}}}\right)^{0.75}$

where $\mathrm{Re}_{\mathrm{p}}$ is the particle Reynolds number.

Valid for:

$25<\operatorname{Re}_{\mathrm{p}}<5000,8<\left(\mathrm{D}_{\mathrm{T}} / \mathrm{d}_{\mathrm{p}}\right)<1340$ and $700<\left(\rho_{\mathrm{p}} / \rho_{\mathrm{g}}\right)$ $<4240$.

Kalman et al. (2005)

First Zone:

$$
\operatorname{Re}_{\mathrm{p}}^{*}=5 \mathrm{Ar}^{\frac{3}{7}}, \text { for } \mathrm{Ar}>16.5
$$

Second Zone:

$$
\operatorname{Re}_{\mathrm{p}}^{*}=16.7, \text { for } 0.45<\mathrm{Ar}<16.5
$$

Third Zone:

$$
\mathrm{Re}_{\mathrm{p}}^{*}=21.8 \mathrm{Ar}^{\frac{1}{3}}, \quad \text { for } \mathrm{Ar}<0.45
$$

\section{Rabinovich and Kalman (2009)}

\section{Non-Spherical Coarse Particle (Drag)}

$$
\begin{aligned}
& \frac{\mathrm{n}}{8} \pi \mathrm{C}_{\mathrm{D}} \operatorname{Re}_{\mathrm{p}}{ }^{2}+0.1 \mathrm{f}_{\mathrm{s}}\left(\frac{\mathrm{d}_{\mathrm{p}}}{\mathrm{D}_{\mathrm{T}}}\right)^{0.29} \\
& \operatorname{Re}^{2.02}-\frac{1}{6} \pi \mathrm{f}_{\mathrm{s}} \mathrm{Ar}=0
\end{aligned}
$$

\section{Spherical Coarse Particle (Rolling)}

$$
\begin{aligned}
& \frac{\mathrm{n}}{8} \pi \mathrm{C}_{\mathrm{D}} \operatorname{Re}_{\mathrm{p}}^{2}+0.1 \mathrm{f}_{\mathrm{s}}\left(\frac{\mathrm{d}_{\mathrm{p}}}{\mathrm{D}_{\mathrm{T}}}\right)^{0.29} \\
& \operatorname{Re}^{2.02}-\frac{1}{6} \pi \mathrm{f}_{\mathrm{s}} \operatorname{Ar} \frac{\mathrm{d}_{\mathrm{p}}}{2}=0
\end{aligned}
$$

\section{Fine particle}

$$
0.0277 n \operatorname{Re}_{50}{ }^{1.96}+0.00635\left(\frac{d_{p}}{D_{T}}\right)^{0.375}
$$

$\operatorname{Re}^{2.625}=\frac{\pi}{6} \mathrm{Ar}+\frac{1}{12} \frac{\mathrm{A}_{\mathrm{h}} \rho_{\mathrm{f}} \mathrm{d}_{\mathrm{p}}}{\mathrm{s}^{2} \mu^{2}}$

where,

$$
\operatorname{Re}_{\mathrm{p}}^{*}=\frac{\rho_{\mathrm{f}} \mathrm{U}_{\mathrm{p}} \mathrm{d}_{\mathrm{p}}}{\mu\left(1.4-0.8 \mathrm{e}^{-\frac{\mathrm{D}_{\mathrm{T}} / \mathrm{D} \mathrm{T} 50}{1.5}}\right)}
$$

where $\mathrm{D}_{\mathrm{T} 50}$ is a $50 \mathrm{~mm}$ pipe diameter.

Valid for:

$0.5<\operatorname{Re}_{\mathrm{p}}^{*}<5400,2 \times 10^{-5}<\mathrm{Ar}<8.7 \times 10^{7}, 0.53<\mathrm{d}_{\mathrm{p}}<$ $3675 \mu \mathrm{m}, 1119<\rho_{\mathrm{s}}<8785 \mathrm{~kg} / \mathrm{m}^{3}$ and $1.18<\rho_{\mathrm{g}}<$ $2.04 \mathrm{~kg} / \mathrm{m}^{3}$. where $A_{H}$ is the Hamaker constant, $n$ is the wall effect coefficient, $f_{s}$ is the friction coefficient and $\mathrm{Re}_{50}$ is the Reynolds number for the pickup velocity measured in a pipe of $50 \mathrm{~mm}$ in diameter.

\section{COMPARISON OF CORRELATIONS FOR THE SALTATION VELOCITIES}

In order to analyze the accuracy of the correlation in predicting the saltation velocities, numerical testing was carried out for all of the referenced correlations. In all simulations air was the transport 
gas at ambient conditions $\left(\rho=1.18 \mathrm{~kg} / \mathrm{m}^{3}\right)$. These analyses were designed to assess the influence of average particle diameter, pipeline diameter and solids mass flow rate at the saltation velocity, thus providing evidence for the indication of the best correlations in specific design situations.

\section{Influence of Particle Diameter}

Figure 2 presents a plot of the saltation velocity as a function of the average diameter of fine particles $(0-200 \mu \mathrm{m})$. The mass flow rate of solids $(\mathrm{Ws}=350$ $\mathrm{kg} / \mathrm{h}$ ) was kept constant in all simulations. An inner diameter of $50.4 \mathrm{~mm}$ for the horizontal pipeline was used. Sand particles were used $\left(\rho_{p}=2636 \mathrm{~kg} / \mathrm{m}^{3}\right)$ in all simulations. The result indicate that only the Rizk (1976) correlation presented a variation with the increase of the average particle diameter, which suggests that all other correlations are not appropriate for predicting pickup velocity throughout a wide range of average particle diameters. It was also observed that the correlation of Rizk (1976) follows the physical behavior for the whole range of particle diameters, since for small particle sizes the effect of cohesive forces is higher, requiring a higher velocity for the particle entrainment (Cabrejos and Klinzing, 1994; Hayden et al. 2003; Rabinovich and Kalman, 2009).

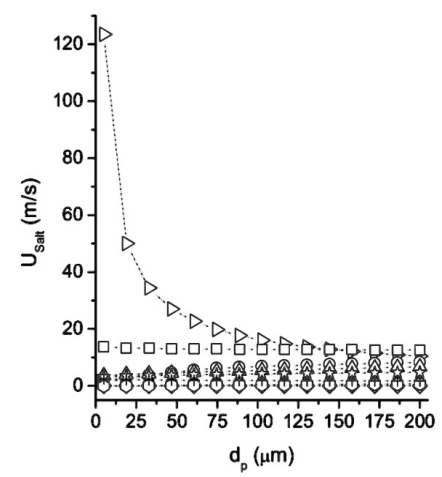

$\triangleright$ Risk (1976)

O... Matsumoto et al (1977)

口. Shade (1987)

$\triangle \cdots$ Weber (1981)

$\checkmark$ Geldart and Ling (1992)

O-.. Ochi (1991)

2.-. Cabrejos and Klinzing (1994)

+... Kalman and Rabinovich (2008) $d_{p}(\mu m)$

Figure 2: Velocity of deposition as a function of average particle size. $d_{p}: 0-200$ micrometers.

Figure 3 shows the plot of saltation velocity as a function of average particle diameter of 200-4000 $\mu \mathrm{m}$. The mass flow rate of solids was maintained constant at $350 \mathrm{~kg} / \mathrm{h}$, and a horizontal pipeline with an inner diameter of $50.4 \mathrm{~mm}$ was used. The average particle diameter ranged from 100 to $4000 \mu \mathrm{m}$. Sand particles were used $\left(\rho_{\mathrm{p}}=2636 \mathrm{~kg} / \mathrm{m}^{3}\right)$ in all simulations. The data indicate that some correlation predict an almost constant saltation velocity (Geldart and Ling, 1992 and Kalman and Rabinovich, 2008), and others very low values for the range from 0 to
$2.5 \mathrm{~m} / \mathrm{s}$. Other correlations (Rizk, 1976; Matsumoto et al., 1977; Weber, 1981; Ochi, 1991; Cabrejos and Klinzing, 1994) showed an increase in the saltation velocity with the increase in average particle diameter. The results of Shade (1987) showed that the saltation velocity decreases with the increase of the average particle diameter, which is not in accordance with the real physical behavior. The comparison between the lowest and highest value of the saltation velocity results in a value of approximately $13 \mathrm{~m} / \mathrm{s}$.

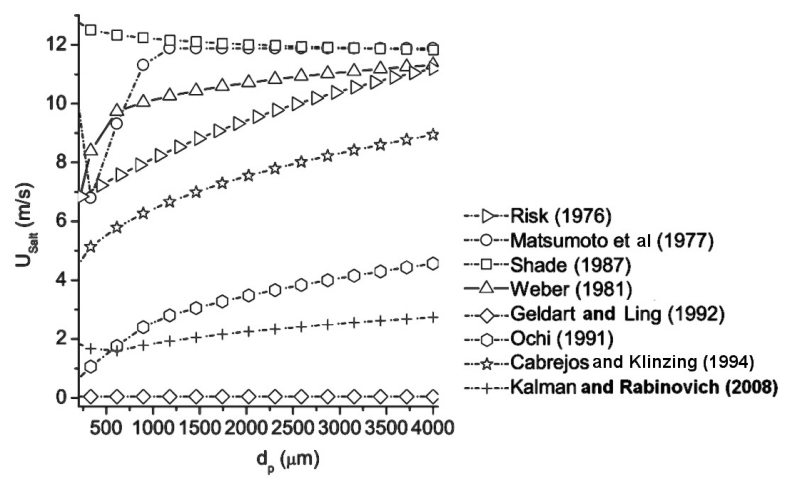

Figure 3: Velocity of deposition as a function of average particle size. $d_{p}: 200-4000$ micrometers.

\section{Influence of Pipeline Diameter}

Figure 4 shows a plot of saltation velocity as a function of pipeline diameter. The simulations were made with sand particles $\left(\rho_{p}=2636 \mathrm{~kg} / \mathrm{m}^{3}\right)$ with particle diameter $\left(\mathrm{d}_{\mathrm{p}}=200 \mu \mathrm{m}\right)$ at a solid mass flow rate of $350 \mathrm{~kg} / \mathrm{s}$. A great discrepancy in the results was found. Some correlations provide a practically constant saltation velocity estimation (Geldart and Ling, 1992; Ochi, 1991), showing low values for the range from 0 to $1 \mathrm{~m} / \mathrm{s}$. Other correlations (Rizk, 1976; Shade, 1987; Matsumoto et al., 1977; Cabrejos and Klinzing, 1994; Kalman et al., 2005) show an increase with the diameter of the pipeline.

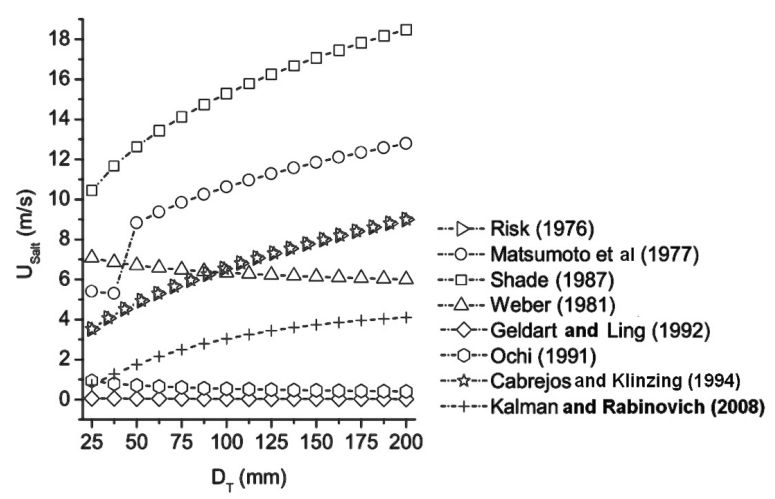

Figure 4: Saltation velocity as a function of pipeline diameter. 
Conversely, other correlation (Weber, 1981; Ochi, 1991; Geldart and Ling, 1992) show a decrease in the saltation velocity when the pipeline diameter was increased. The difference between the highest and lowest saltation velocity value for a pipe diameter of $200 \mathrm{~mm}$ is approximately $19 \mathrm{~m} / \mathrm{s}$.

\section{Influence of the Solids Mass Flow Rate}

Figure 5 shows a plot of saltation velocity as a function of mass flow rate for solid particles of sand $\left(\rho_{p}=2636 \mathrm{~kg} / \mathrm{m}^{3}\right)$. The simulations were carried out for particle and pipeline diameters of $200 \mu \mathrm{m}$ and $50.4 \mathrm{~mm}$, respectively. The range for the solid mass flow employed was from 50 to $1000 \mathrm{~kg} / \mathrm{s}$. Some correlations (Geldart and Ling, 1992; Ochi, 1991; Kalman et al., 2008) remained constant in the range of very low saltation velocity values (between 0 and $2 \mathrm{~m} / \mathrm{s}$ ) and other correlations show growth with an increase in solid mass flow (Weber, 1981; Cabrejos and Klinzing, 1994; Matsumoto et al., 1977; Rizk, 1976; Shade, 1987). The saltation velocity values are very divergent. The difference between the highest and lowest saltation velocity for the solid mass flow rate of $1000 \mathrm{~kg} / \mathrm{s}$ was about $14 \mathrm{~m} / \mathrm{s}$.

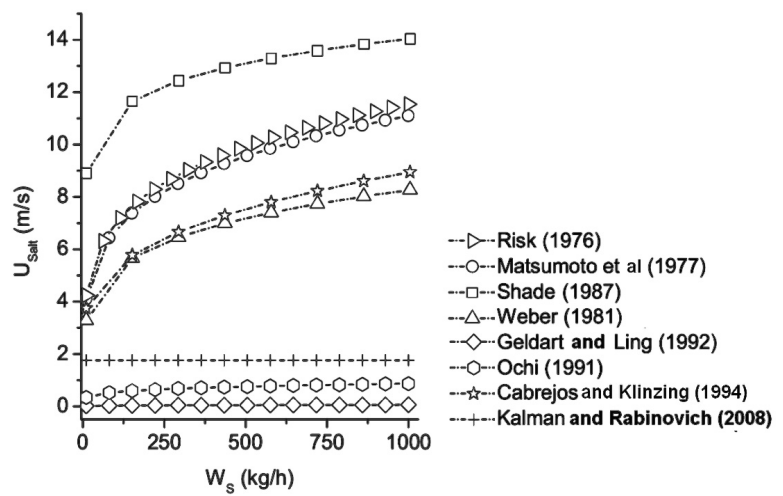

Figure 5: Saltation velocity as a function of the solids mass flow rate.

\section{COMPARISON OF THE PICKUP VELOCITY CORRELATIONS}

For the determination of the pickup velocity, four significant correlations available in the literature were evaluated. In all simulations air was used $\left(\rho_{\mathrm{f}}=\right.$ $1.18 \mathrm{~kg} / \mathrm{m}^{3}$ ) as the transporter gas. The goal of the simulations was to analyze the influence of the particle size, pipe diameter and particle density. This was accomplished by varying one parameter and keeping the others constant. In order to support this analysis, experimental work was also carried out. In the following section the testing bench is described, as well the characteristics of the materials used.

\section{The Experimental Setup}

An experimental apparatus, see Figure 6, was developed to determine the pickup velocity, which consists basically a 1.5 -meter-long, $50 \mathrm{~mm}$ diameter horizontal steel pipeline; three horizontal PVC pipelines (each 6 meters long and 50, 75 and $100 \mathrm{~mm}$ in diameter), with a butterfly valve at the end of each pipeline; three transparent sections (placed in the middle of the PVC pipelines, where the visual observations were carried out); a root blower (controlled by a frequency inverter), which provides the gas flow rate and pressure necessary for picking up the particles; and a solids collector with a paper filter bag placed on its top. A complete description of this experimental setup can be found in Gomes (2011). Experiments were carried out using air as the conveying gas at ambient conditions.

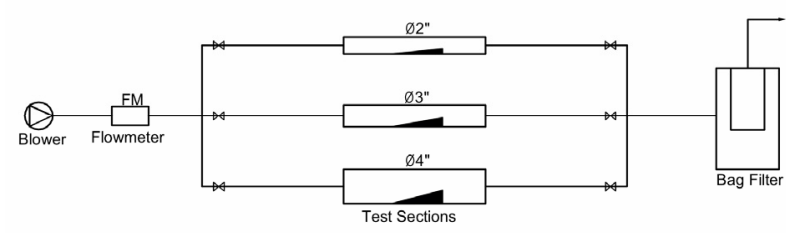

Figure 6: Schematic representation of the experimental setup.

The experimental run starts with a stationary layer of particles placed in the central section of a transparent pipe. Air flow is initiated at a constant volumetric flow rate through the pipe. As the free cross-sectional area of the pipe increases, the air velocity decreases due to the removal of the particles. When the velocity is no longer sufficient to entrain any additional particles, a final state of equilibrium is automatically reached. This procedure is repeated until nearly 95 per cent of the whole material has been captured. Plotting the amount of entrained particles (weight reduction of the layer) as a function of operating gas velocity made it possible to determine the pickup velocity by the intersection of the extrapolated curve passing through the measured points and abscissa (see Figure 7). Obviously, a higher number of measurements will improve the accuracy, especially if determinations with very small weight losses are in progress.

In order to assess the effect of pipe diameter on the pickup velocity, three PVC pipelines were used in an alternate manner. Air flow was initiated at a 
constant volumetric flow rate through the pipeline with one of the three butterfly valves opened. The layer started to erode slowly as the gas stream picked up the top particles.

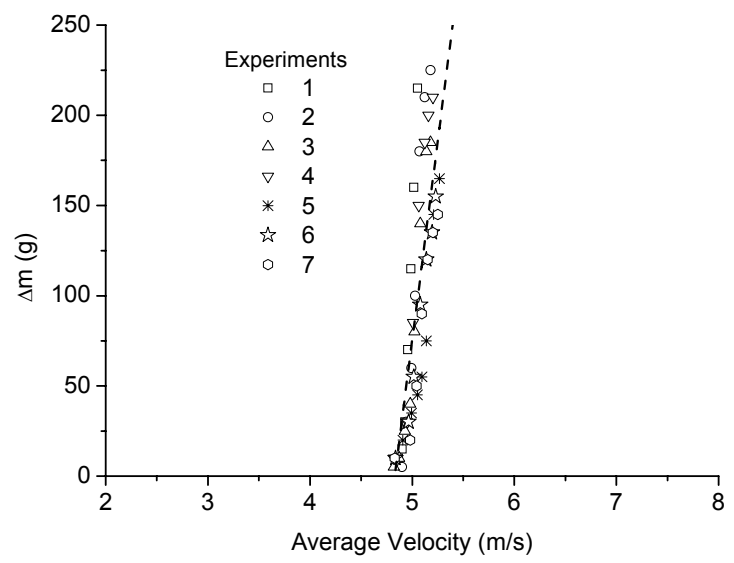

Figure 7: Weight loss as a function of the average air velocity. Experimental data. $\mathrm{dp}=179.5 \mu \mathrm{m}$.

This experiment was performed using sand and alumina particles. The particle diameters used in the tests were obtained by the method of separation by sieves. The mean diameter was calculated as the arithmetic mean of consecutive sieve openings. Figures 8-9 show the sand and alumina particles with non-spherical shape. Table 1 presents the properties (density, size distribution, mean diameter and shape) and Geldart classification of the particles used in the measurements. The density was measured with a pycnometer. All tests were conducted with a narrow range of particle sizes prepared by sieving.

Table 2 shows experimental data used in this paper for the pickup velocity study.

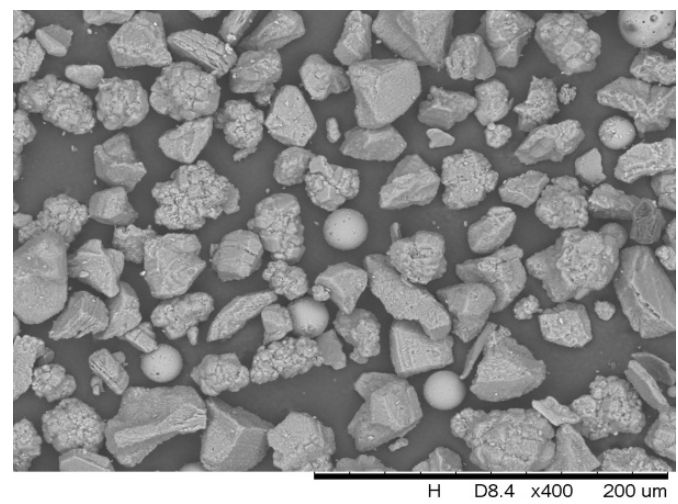

UFPA-FEMAT

Figure 8: Alumina particles, $d_{p}=62 \mu \mathrm{m}$.

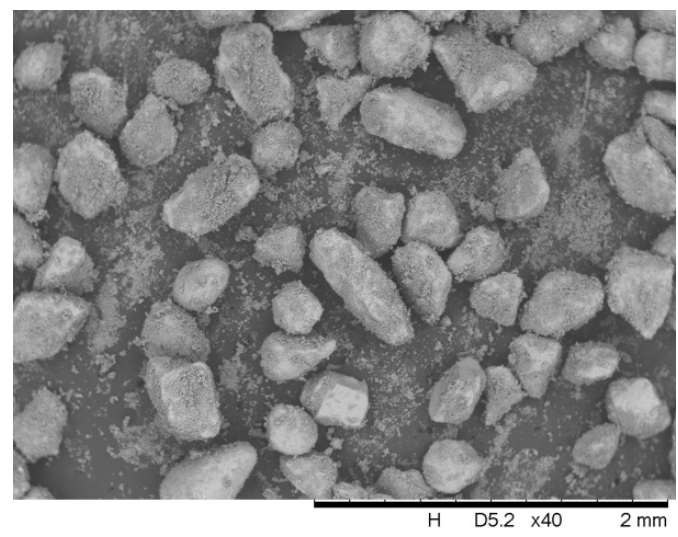

UFPA-FEMAT

Figure 9: Sand grains, $d_{p}=340 \mu \mathrm{m}$.

Table 1: Properties of the particles tested in this research.

\begin{tabular}{|c|c|c|c|c|}
\hline Particle & $\begin{array}{l}\text { Density } \\
\left(\mathrm{kg} / \mathrm{m}^{3}\right)\end{array}$ & $\begin{array}{l}\text { Size range } \\
(\mu \mathrm{m})\end{array}$ & $\begin{array}{c}\text { Mean Diameter } \\
(\mu \mathrm{m})\end{array}$ & Sphericity \\
\hline Sand & 2636 & $\begin{array}{c}50-90 \\
90-150 \\
150-250 \\
250-430 \\
600-430 \\
600-850 \\
850-1000 \\
1000-2360 \\
2360-3350 \\
3350-4360\end{array}$ & $\begin{array}{c}70 \\
120 \\
200 \\
340 \\
510 \\
730 \\
930 \\
1680 \\
2860 \\
3860\end{array}$ & $\psi=0.7$ \\
\hline Alumina & 3750 & $\begin{array}{r}53-90 \\
90-125 \\
125-150 \\
150-205\end{array}$ & $\begin{array}{r}71.5 \\
107.5 \\
137.5 \\
177.5\end{array}$ & $\Psi=0.9$ \\
\hline
\end{tabular}


Table 2: Experimental data used in this paper for the pickup velocity study and Geldart Classification.

\begin{tabular}{|l|c|c|c|}
\hline Material & $\begin{array}{c}\text { Density } \\
\left(\mathbf{k g} / \mathbf{m}^{\mathbf{3}} \mathbf{)}\right.\end{array}$ & $\begin{array}{c}\text { Sizes } \\
\mathbf{( \boldsymbol { \mu m } )}\end{array}$ & $\begin{array}{c}\text { Geldart } \\
\text { Classification }\end{array}$ \\
\hline sand & 2636 & $70-3860$ & $\mathrm{~A} ; \mathrm{B} ; \mathrm{C} ; \mathrm{D}$ \\
alumina & 3750 & $71.5-177.5$ & $\mathrm{~A} ; \mathrm{B}$ \\
glass beads & 2834 & $200-3500$ & $\mathrm{~B} ; \mathrm{D}$ \\
salt irregular & 2234 & $200-3500$ & $\mathrm{~B} ; \mathrm{D}$ \\
non-spherical glass & 2834 & $200-3500$ & $\mathrm{~B} ; \mathrm{D}$ \\
pasta & 1200 & 5400 & $\mathrm{~B} ; \mathrm{D}$ \\
spaghetti & 1500 & 4100 & $\mathrm{D}$ \\
lentil & 1644 & 3830 & $\mathrm{D}$ \\
rice & 1590 & 2940 & $\mathrm{D}$ \\
bakelite & 930 & 2700 & $\mathrm{D}$ \\
\hline
\end{tabular}

Figure 10 presents the plot of the pickup velocity as a function of average particle diameter. A pipe diameter of $50.4 \mathrm{~mm}$ and a particle diameter ranging from 200 to $3500 \mu \mathrm{m}$ were employed in the simulations. Experimental data are compared for sand particles $\left(\rho_{p}=2636 \mathrm{~kg} / \mathrm{m}^{3}\right)$, glass beads $\left(\rho_{\mathrm{p}}=2834 \mathrm{~kg} / \mathrm{m}^{3}\right)$ and irregular grains of salt $\left(\rho_{p}=2234 \mathrm{~kg} / \mathrm{m}^{3}\right)$ with a pickup velocity of sand particles $\left(\rho_{\mathrm{p}}=2636 \mathrm{~kg} / \mathrm{m}^{3}\right)$ obtained from Cabrejos and Klinzing (1992), Cabrejos and Klinzing (1994), Kalman et al. (2005) and correlations from Kalman et al. (2009).

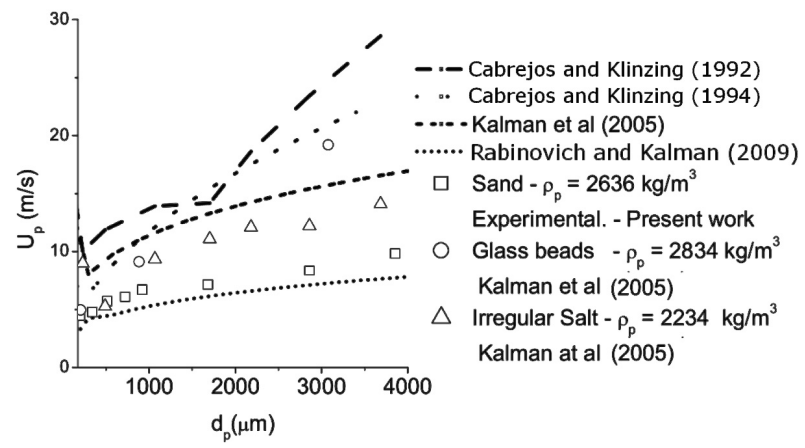

Figure 10: Experimental pickup velocity as a function of the particle diameter and correlation curves. $\mathrm{d}_{\mathrm{p}}$ : 200-3500 $\mu \mathrm{m}$.

From an analysis of the curves obtained with the use of the above mentioned correlations, it was verified that all of them show an increase in the pickup velocity as the average particle diameter is increased. However, for a given average particle size, there is a large divergence between the values of pickup velocities obtained and values predicted by the correlations. This shows that such correlations present limitations in predicting reliable values of pickup velocities. It is noted that three correlations present a fair agreement among themselves for predicting the pickup velocity up to approximately the average particle diameter of $1500 \mu \mathrm{m}$. For particle diameters above this limiting value, the results begin to diverge considerably. The values obtained with the correlations of Rabinovich and Kalman (2009) are usually very low and those obtained with the correlation of Cabrejos and Klinzing (1992) for particle average diameter above $1500 \mu \mathrm{m}$ rise very quickly. It should be noted here that the correlation of Cabrejos and Klinzing (1992) was obtained from a theoretical model and some of the parameters were adjusted empirically. The correlation of Cabrejos and Klinzing (1994) is fully empirical. Note also that the correlations of Cabrejos and Klinzing (1994) and Kalman et al. (2005) agree reasonably well with each other. All correlations agree reasonably well with the experimental data, although the correlations by Cabrejos and Klinzing (1994) and Kalman et al. (2005) show a better fit when the whole range of particle diameter is considered.

Figure 11 presents the plot of the pickup velocity as a function of average particle diameter for fine particles. The simulations were made with data for sand particles $\left(\rho_{p}=2636 \mathrm{~kg} / \mathrm{m}^{3}\right)$ and the results compared with experimental data for non-spherical glass $\left(\rho_{\mathrm{p}}=2834 \mathrm{~kg} / \mathrm{m}^{3}\right)$, irregular salt $\left(\rho_{\mathrm{p}}=2234 \mathrm{~kg} / \mathrm{m}^{3}\right)$, sand $\left(\rho_{p}=2636 \mathrm{~kg} / \mathrm{m}^{3}\right)$ and glass beads $\left(\rho_{\mathrm{p}}=2834 \mathrm{~kg} / \mathrm{m}^{3}\right)$. The pipeline diameter used in the simulations was $50.4 \mathrm{~mm}$. The equation of Rabinovich and Kalman (2009) presents no correlation with the physical phenomenon, since for the smallest particle diameters the pickup velocity should increase with the reduction of the average diameter of the particles, which does not occur. The correlation that provides the best agreement with experimental data (which includes an average particle diameter ranging from 0 to $200 \mu \mathrm{m}$ ) is the correlation of Kalman et al. (2005). It is noteworthy to point out that, for the average diameter of $22 \mu \mathrm{m}$, the error of this correlation is approximately $100 \%$. The correlation of Cabrejos and Klinzing (1992) overestimates the results, considerably. 


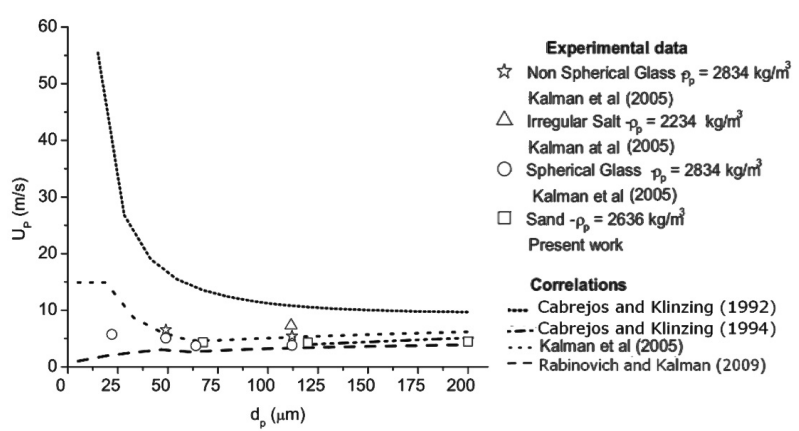

Figure 11: Pickup velocity as function the diameter of the particles. $d_{p}: 0-200 \mu \mathrm{m}$

\section{Influence of Pipe Diameter}

Figure 12 presents the plot of the particle pickup velocities of irregular shaped polyester beads $\left(\rho_{p}=\right.$ $1400 \mathrm{~kg} / \mathrm{m}^{3}$ and $\left.\mathrm{d}_{\mathrm{p}}=3 \mathrm{~mm}\right)$, glass beads $\left(\rho_{\mathrm{p}}=2480\right.$ $\mathrm{kg} / \mathrm{m}^{3}$ and $\mathrm{d}_{\mathrm{p}}=0.45 \mathrm{~mm}$ ) and non-spherical alumina $\left(\rho_{p}=3750 \mathrm{~kg} / \mathrm{m}^{3}\right.$ and $\left.\mathrm{d}_{\mathrm{p}}=0.45 \mathrm{~mm}\right)$, as a function of the pipeline diameter obtained with the use of the correlations of Cabrejos and Klinzing (1992), Cabrejos and Klinzing (1994), Kalman et al. (2005) and Rabinovich and Kalman (2009). The results obtained are compared with experimental data obtained by Cabrejos and Klinzing (1994). It is found that the correlation of Rabinovich and Kalman (2009) presents a behavior totally different from the other correlations, i.e., the pickup velocity decreases with increasing pipeline diameter. Values obtained with this correlation are also extremely low. The values obtained with the correlation of Cabrejos and Klinzing (1992) for the irregular polyester particles are farther above the experimental results. The results obtained for glass beads and spherical alumina do not agree with the experimental data. The correlations of Cabrejos and Klinzing (1994) and Kalman et al. (2005) present a better fit with experimental values.

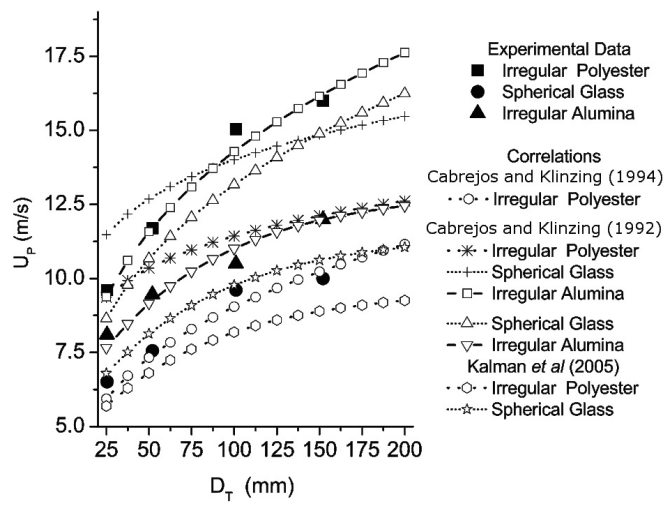

Figure 12: Pickup velocity as a function of pipeline diameter.

\section{Influence of Particle Density}

Figure 13 presents the plot of pickup velocity as a function of the density of sand particles with an average diameter of $1.0 \mathrm{~mm}$. In the simulations the pipeline diameter was equal to $50.4 \mathrm{~mm}$. The correlations of Cabrejos and Klinzing (1992) and Rabinovich and Kalman (2009) show the highest and lowest pickup velocities, respectively. For the density of $5000 \mathrm{~kg} / \mathrm{m}^{3}$ the difference between the highest and lowest pickup velocity is approximately $16 \mathrm{~m} / \mathrm{s}$.

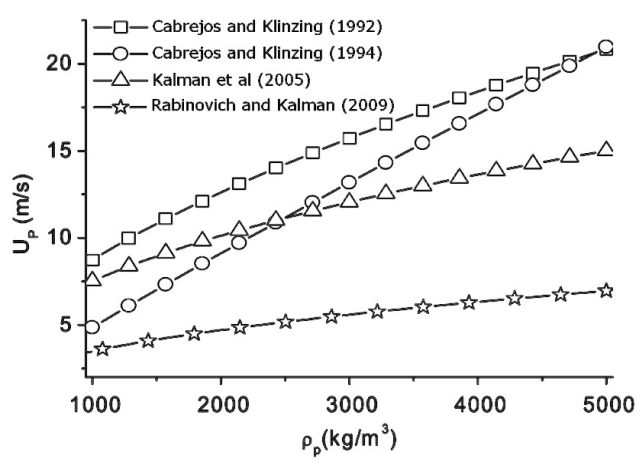

Figure 13: Pickup velocity as a function of particle density.

Figure 14 shows the plot of the pickup velocity as a function of particle diameter for particles of sand and alumina. The experimental data were obtained in this work. Correlations with the best agreement with the experimental data are Cabrejos and Klinzing (1994) and Kalman et al. (2005).

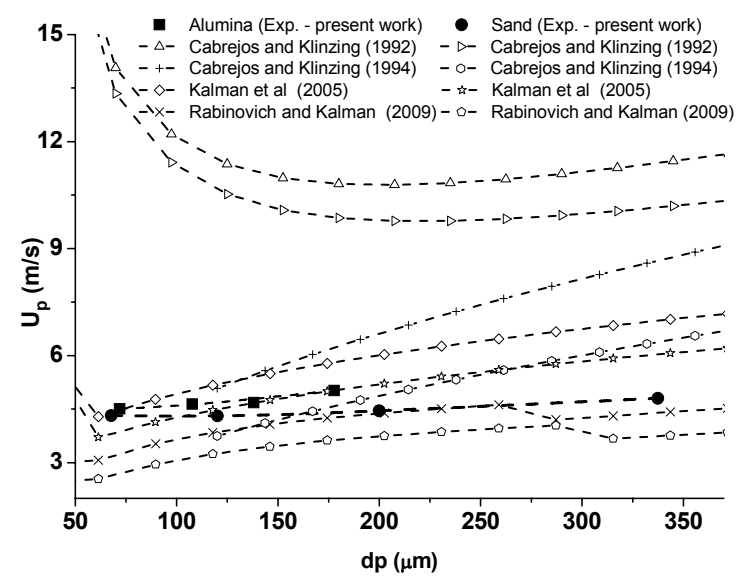

Figure 14: Pickup velocity as a function of particle density.

\section{Influence of the Particles Sphericity}

Figure 15 shows the pickup velocity as a function of sphericity for pasta $\left(\rho_{p}=1200 \mathrm{~kg} / \mathrm{m}^{3}\right)$, spaghetti 
$\left(\rho_{\mathrm{p}}=1500 \mathrm{~kg} / \mathrm{m}^{3}\right)$, lentil $\left(\rho_{\mathrm{p}}=1644 \mathrm{~kg} / \mathrm{m}^{3}\right)$, rice $\left(\rho_{p}=1590 \mathrm{~kg} / \mathrm{m}^{3}\right)$ and bakelite $\left(\rho_{\mathrm{p}}=930 \mathrm{~kg} / \mathrm{m}^{3}\right)$ particulate materials. The analysis was performed only with the Kalman's correlation (Kalman et al., 2005), since it presents a dependence of pickup velocity on sphericity. To obtain the experimental data, a pipe with a $100 \mathrm{~mm}$ diameter was used. The correlation shows reasonable agreement with experimental data. However, a careful observation of this correlation demonstrates that the pickup velocity decreases with decreasing sphericity (keeping other parameters constant), which is in contradiction to the physical phenomena involved, since the pickup velocity should increase with the reduction of the sphericity (Cabrejos and Klinzing, 1992; Cabrejos and Klinzing, 1994; Hayden et al., 2003) and not the opposite, as is the case of this correlation (see Figure 16).

Figure 16 shows the pickup velocity as a function of particle diameter for pipe diameters of 25 and 52 $\mathrm{mm}$. The materials used were spherical and nonspherical glass. The experimental data are obtained from Cabrejos and Klinzing (1994), Hayden et al. (2003) and Kalman et al. (2005). The densities are 2480, 2500 and $2834 \mathrm{~kg} / \mathrm{m}^{3}$, respectively. The sphericity of the non-spherical glass is 0.7 (Cabrejos and Klinzing, 1994). Note that the non-spherical glass has greater velocities than the glass spheres in both pipe diameters of 25 and $50 \mathrm{~mm}$. This is due to the fact that, in the case of non-spherical particles, the contact area is larger and therefore there is a greater action of the cohesion forces (Cabrejos and Klinzing, 1994; Hayden et al., 2003; Kalman et al., 2005). In Kalman's correlation (Kalman et al., 2005) the pickup velocities of spherical particles are always larger than those for non-spherical particles, thus showing that the reasonable agreement obtained in the pickup velocity from experimental data was related to its correlation with other parameters and not necessarily with the sphericity.

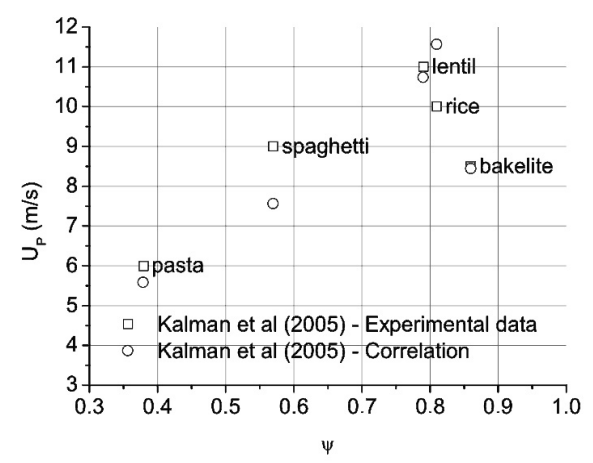

Figure 15: Pickup velocity as a function of the particles sphericity.

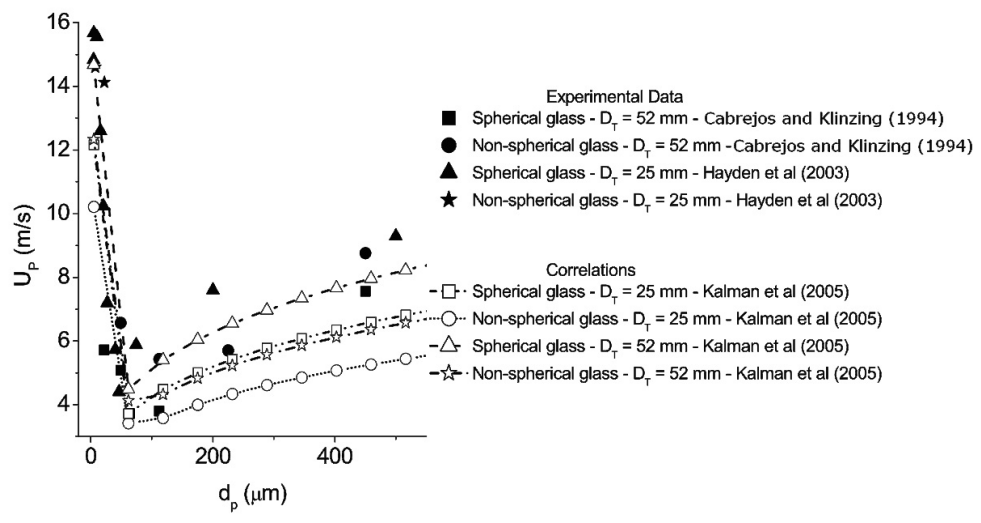

Figure 16: Pickup velocity as a function of particle diameter for pipe diameters of 25 and $52 \mathrm{~mm}$. 


\section{CONCLUSION}

Due to the different definitions of the minimum conveying velocity used by researchers and the wide scatter of the data and contradictions demonstrated in this paper, it is concluded that the correlations analyzed present great difficulty in predicting the saltation and pickup velocities. The recommendations presented in this work are based on combined quantitative and qualitative analysis, so both the agreement with experimental data (quantitative) as the agreement with the observed physical phenomenon (qualitative) are considered. Based on the analysis of the parameters that influence saltation and pickup velocities, one may conclude that:

- In the case of fine particles, the only correlation recommended for saltation velocity is the Rizk correlation (1976), since the others do not agree with the physical phenomenon in question.

- It is recommended that the correlations of Rizk (1976), Matsumoto et al. (1977) and Cabrejos and Klinzing (1994) be used in determining the saltation velocity of coarse particles (average particle diameter above $200 \mu \mathrm{m}$. The use of these correlations should still be considered for pipeline diameters ranging from 25 to $200 \mathrm{~mm}$. It is noteworthy that the use of these correlations must be done with great care, since in some tests even the best correlations (those recommended here) showed low agreement with the experimental results. Nonetheless, these correlations presented the best results, but are recommended here with reservations;

- The correlations that presented the best performance for the pickup velocity prediction are those of Cabrejos and Klinzing (1994) and Kalman et al. (2005). However, they are limited to a few tests. The Cabrejos correlation (Cabrejos and Klinzing, 1994) has the disadvantage of not providing results for very low average particle diameter (below $120 \mu \mathrm{m}$ ) and also has a tendency to overestimate particle pickup velocity for very large diameters (up to $3 \mathrm{~mm}$ ). The Cabrejo correlation must be used with caution. Thus, we recommend Kalman's correlation for predicting pickup velocity, because it showed reasonable success in all tests, except in correlating the influence of sphericity, where it was inefficient.

\section{ACKNOWLEDGEMENTS}

The authors would like to express their gratitude for the financial support from CNPq and FAPESPA.

\section{NOMECLATURE}

\begin{tabular}{|c|c|c|}
\hline A & cross-sectional area of pipe & $\mathrm{m}^{2}$ \\
\hline $\mathrm{A}_{\mathrm{H}}$ & Hamaker constant & N.m \\
\hline $\mathrm{Ar}$ & Archimedes number & - \\
\hline $\mathrm{C}_{\mathrm{D}}$ & drag coefficient & - \\
\hline $\mathrm{C}_{\mathrm{V}}$ & Solids volumetric concentration & - \\
\hline $\mathrm{D}_{50}$ & inside diameter of 2" pipe & $\mathrm{m}$ \\
\hline$d_{p}$ & particle diameter & $\mathrm{m}$ \\
\hline $\mathrm{D}_{\mathrm{T}}$ & pipe diameter & $\mathrm{m}$ \\
\hline $\mathrm{Fr}_{\text {min }}$ & $\begin{array}{l}\text { Froude number at the minimum } \\
\text { conveying velocity }\end{array}$ & \\
\hline $\mathrm{Fr}_{\mathrm{S}}$ & $\begin{array}{l}\text { Froude number at the Saltation } \\
\text { velocity }\end{array}$ & - \\
\hline $\mathrm{f}_{\mathrm{s}}$ & coefficient of sliding friction & \\
\hline $\mathrm{g}$ & acceleration due to gravity & $\mathrm{m} / \mathrm{s}^{2}$ \\
\hline $\mathrm{G}_{\mathrm{S}}$ & solids flux & $\mathrm{kg} / \mathrm{m}^{2} . \mathrm{s}$ \\
\hline $\mathrm{m}_{\mathrm{p}}$ & particle mass & $\mathrm{kg}$ \\
\hline $\mathrm{n}$ & Wall effect coefficient & \\
\hline $\operatorname{Re}$ & $\begin{array}{l}\text { Reynolds number related to pipe } \\
\text { diameter }\end{array}$ & \\
\hline $\mathrm{Re}_{\mathrm{p}}$ & $\begin{array}{l}\text { Reynolds number related to } \\
\text { particle diameter }\end{array}$ & \\
\hline $\operatorname{Re}_{\mathrm{p}}{ }^{*}$ & $\begin{array}{l}\text { Reynolds number modified } \\
\text { separation length between }\end{array}$ & - \\
\hline s & particle and the wall & \\
\hline $\mathrm{U}_{\min }$ & minimum conveying velocity & $\mathrm{m} / \mathrm{s}$ \\
\hline $\mathrm{U}_{\mathrm{mp}}$ & minimum pressure velocity & $\mathrm{m} / \mathrm{s}$ \\
\hline $\mathrm{U}_{\mathrm{p}}$ & minimum pickup velocity & $\mathrm{m} / \mathrm{s}$ \\
\hline $\mathrm{U}_{\mathrm{p} 0}$ & $\begin{array}{l}\text { minimum pickup velocity for } \\
\text { single particle }\end{array}$ & $\mathrm{m} / \mathrm{s}$ \\
\hline $\mathrm{U}_{\mathrm{S}}$ & Saltation velocity & $\mathrm{m} / \mathrm{s}$ \\
\hline $\mathrm{U}_{\mathrm{s} 0}$ & $\begin{array}{l}\text { Saltation velocity of an isolated } \\
\text { particle }\end{array}$ & $\mathrm{m} / \mathrm{s}$ \\
\hline $\mathrm{U}_{\mathrm{t}}$ & terminal velocity & $\mathrm{m} / \mathrm{s}$ \\
\hline $\mathrm{W}_{\mathrm{S}}$ & solids mass flow rate & $\mathrm{kg} / \mathrm{s}$ \\
\hline
\end{tabular}

\section{Greek Letters}

$\begin{array}{llr}\varepsilon & \text { porosity } & - \\ \zeta & \text { solids loading ratio } & - \\ \mu & \text { gas dynamic viscosity } & \mathrm{kg} / \mathrm{ms} \\ \nu & \text { fluid kinematic viscosity } & \mathrm{m}^{2} / \mathrm{s} \\ \rho_{\mathrm{f}} & \text { fluid density } & \mathrm{kg} / \mathrm{m}^{3} \\ \rho_{\mathrm{p}} & \text { solid particle density } & \mathrm{kg} / \mathrm{m}^{3} \\ \psi & \text { Particle sphericity } & -\end{array}$

\section{REFERENCES}

Cabrejos, F. J., Klinzing, G. E., Incipient motion of solid particles in horizontal pneumatic conveying. Powder Technology, v. 72, pp. 51-61 (1992). 
Cabrejos, F. J., Klinzing, G. E., Pickup and saltation mechanisms of solids particles in horizontal pneumatic transport. Powder Technology, v. 79, pp. 173-186 (1994).

Chu, K. W., Yu, A. B., Numerical simulation of complex particle-fluid flows. Powder Technology, v. 179, pp. 104-114 (2008).

Gomes, L. M., Contribution to the Dilute-Phase Pneumatic Conveying Analysis. PhD Thesis, Federal University of Pará, Brazil (2011). (In Portuguese).

Geldart, D., Liung, S. J., Saltation in high pressure conveying of fine coal. Powder Technology. v. 69, pp. 157-162 (1992).

Hayden, K. S., Park, K., Curtis, J. S., Effect of particle characteristics on particle pickup velocity. Powder Technology, v. 131, pp. 7-14 (2003).

Huilin, L., Gidaspow, D., Bouillard, J., Wentie, L., Hydrodynamic modelling of gas-solid flow in a riser using the kinetic theory of granular flow. Chemical Engineering Journal, v. 95, pp. 1-13, (2003).

Kalman, H., Satran, A., Meir, D., Rabinovich, E., Pickup (critical) velocity of particles. Powder Technology, v. 160, pp. 103-113 (2005).

Kalman, H., Rabinovich, E., Boundary saltation and minimum pressure velocities in particle-gas systems. Powder Technology, v. 185, pp. 67-79 (2008).

Matsumoto, S., Hara, M., Saito, S. and Maeda, S., Minimum transport velocity for horizontal pneumatic conveying. Journal of Chemical Engineering of Japan, v. 7 n. 6, pp. $425-431$ (1977).

Ochi, M., Saltation velocity of the gas-solid two- phase flow in a horizontal pipe. Proc. The First ASME-JSME Fluids Engineering Conference, FED-121, pp. 163-166 (1991).

Pirker, S., Kahrimanovic, D., Kloss, C., Popoff, B., Braum, M., Simulations coarse particle conveying by a set of Eulerian, lagrangian and hybrid particle models. Powder Technology, v. 204, pp. 203-213 (2010).

Rabinovich, E., Kalman, H., Generalized master curve for threshold superficial velocities in particle-fluid systems. Powder Tecnology, v. 183, pp. 304-313(2008).

Rabinovich, E., Kalman, H., Incipient motion of individual particles in horizontal particle-fluid systems: B. Theoretical analysis. Powder Tecnology, v. 192, no 3, pp. 326-338 (2009).

Rizk, F., Pneumatic conveying at optimal operation conditions and a solution of Bath's equation. Proc Pneumotransport, 3, Bath, England, pp. 443-58 (1976).

Schade, B., Zum Übergang Sprung-Strähnenförderung bei der Horizontalen Pneumatischen Feststoffördrung. Dissertation, University of Karlsruche (1987) apud Yi, J., Wypych, P. W., Pan, R., Minimum Conveying Velocity in DilutePhase Pneumatic Conveying, Powder Handling \& Processing, v. 10, n. 3, pp. 255-261 (1998).

Yi, J., Wypych, P. W., Pan, R., Minimum conveying velocity in dilute-phase pneumatic conveying. Powder Handling \& Processing, v. 10, n. 3, pp. 255-261 (1998).

Weber, M., Principles of hydraulic and pneumatic conveying in pipes. Bulk Solids Handling, v. 1, pp. 57-63 (1981). 